\title{
Nitrogen Response Index as a Guide to Fertilizer Management ${ }^{\#}$
}

\author{
G. V. Johnson* and W. R. Raun
}

Department of Plant and Soil Sciences, Oklahoma State University, Stillwater, Oklahoma

\begin{abstract}
The efficiency with which fertilizer-nitrogen $(\mathrm{N})$ is transferred to grain-N in cereals is usually less than $50 \%$ and averages $33 \%$ worldwide. Two long-term $\mathrm{N}$ fertility experiments were evaluated to examine temporal changes in nitrogen use efficiency (NUE) and their causes. Averaged over 30 -yr, non-irrigated winter wheat NUE was $49 \%$ at a $22.4 \mathrm{~kg} \mathrm{Nha}^{-1} \mathrm{yr}^{-1}$ rate and decreased to $34 \%$ at a rate of $112 \mathrm{~kg} \mathrm{Nha}^{-1} \mathrm{yr}^{-1}$. The average NUE for a $15-\mathrm{yr}$ irrigated corn experiment was $30.6 \%$ at the lowest $\mathrm{N}$ input $\left(90 \mathrm{~kg} \mathrm{Nha}^{-1}\right)$ and decreased to $18.3 \%$ at a rate of 270 $\mathrm{kg} \mathrm{Nha}^{-1} \mathrm{yr}^{-1}$. Low NUE values are a result of excess $\mathrm{N}$ present in the soil-plant system. The extent to which $\mathrm{N}$ is present in excess is determined by the potential yield and how much of that yield will be supported by non-fertilizer $\mathrm{N}$, presumably mineralized from soil organic matter. For both experiments there was greater temporal variability in nonfertilized (check-plot) yields (CV of 31.4 for wheat and 34.3 for corn) than
\end{abstract}

${ }^{\#}$ Contribution from the Oklahoma Agricultural Experiment Station.

${ }^{*}$ Correspondence: G. V. Johnson, Department of Plant and Soil Sciences, Oklahoma State University, Stillwater, OK 74078, USA. E-mail: gvj@mail.pss.okstate.edu. 
MARCEL DEKKER, INC. • 270 MADISON AVENUE • NEW YORK, NY 10016

(C2002 Marcel Dekker. Inc. All rights reserved. This material may not be used or reproduced in any form without the express written permission of Marcel Dekker, Inc.

in plots where maximum yields were obtained from $\mathrm{N}$-fertilizer $(\mathrm{CV}$ of 20.1 for wheat and 15.7 for corn). The yield of unfertilized plots was not related to the maximum yield of fertilizer plots over time. A response index (RI) was calculated by dividing the maximum yield of fertilized plots by the yield of unfertilized plots to determine the extent of fertilizer need and response for a given year. For both wheat and corn the RI was unpredictably variable $(\mathrm{CVs} \approx 35)$ over time, and ranged from lows of about 1.1 to a high of 4.1 for wheat and 3.5 for corn. In general, low RI values resulted when unfertilized yields were high, which even occurred after 10 to $30 \mathrm{yr}$ without $\mathrm{N}$ fertilization. Low RI values may be more common in farmer's fields where $\mathrm{N}$ is applied annually. Except at the lowest $\mathrm{N}$ rates, NUE increases for each rate as RI increases because $\mathrm{N}$ inputs are less likely to be excessive. Nitrogen management strategies that increase NUE may only be possible to evaluate for site-years when RI is substantially greater than 1 (e.g. >1.5). Since response to $\mathrm{N}$ fertilizer is strongly dependant on supply of non-fertilizer $\mathrm{N}$ in a given year, any $\mathrm{N}$ management strategy that includes a reliable in-season predictor of RI should dramatically improve NUE in cereal production.

\section{INTRODUCTION}

A recent review of nitrogen (N) use efficiency (NUE) in cereal production identified worldwide efficiencies of only $33 \%$ for fertilizer-N. ${ }^{[1]}$ The economic importance of improving NUE on a global scale was provided from a calculation showing that raising NUE by $1 \%$ would have a value of $\$ 234,658,462$ in $\mathrm{N}$ fertilizer savings if yields were maintained. Recent increases in the cost of natural gas would raise the estimate to more than $\$ 400,000,000$. As the costs for fertilizer-N continue to increase with increasing natural gas prices, there is even greater merit in close examination and evaluation of causes for poor NUE. The low, worldwide NUE value is in agreement with average values of about $25 \%$ from long-term plot research of maize and sorghum from Nebraska ${ }^{[2]}$ and $40 \%$ for wheat in Oklahoma. ${ }^{[3]}$ Cropping systems, $\mathrm{N}$ source, and method of fertilizer application have been identified as factors influencing NUE, as well as the pathways of N loss from the soil-plant system. ${ }^{[1]}$ In a broad assessment, low NUE is a result of the soil-plant system leaking $\mathrm{N}$ and the leakage occurring in direct proportion to the degree to which mineral $\mathrm{N}$ is present in excess. Fertilizer-N management cannot exclude the natural processes responsible for $\mathrm{N}$ loss by denitrification, leaching, and ammonia $\left(\mathrm{NH}_{3}\right)$ volatilization from soil and plant surfaces. 
However, fertilizer-N management is responsible for the extent to which mineral $\mathrm{N}$ is present in the system in excess. The objective of this study was to determine temporal relationships between NUE and the extent to which crop response to $\mathrm{N}$ existed [response index (RI)] using results from previously published, long-term $\mathrm{N}$ fertilizer trials, for wheat (Triticum aestivum L.) and irrigated corn (Zea mays L.).

\section{MATERIALS AND METHODS}

Crop response data were evaluated from previously described research on wheat ${ }^{[3]}$ and corn. ${ }^{[2]}$ Both studies included evaluation of average yield response to fertilizer-N, but neither examined NUE or fertilizer response by year. Each experiment followed traditional design (randomized complete block, four replications) and implementation [conventional tillage, ammonium nitrate-N applied preplant incorporated (wheat) or urea-ammonium nitrate solution (UAN) knifed preplant (corn)]. The wheat research has been continuous since 1971 on a Grant silt loam (fine-silty, mixed, thermic Udic Argiustoll) at the Oklahoma Agricultural Experiment Station Field Laboratory near Lahoma, OK. Fertilizer was applied at rates of $0,22,45,67,90$, and $112 \mathrm{~kg} \mathrm{Nha}^{-1}$ on plots 4.9 by $18.3 \mathrm{~m}$. Profile sampling to $2.1 \mathrm{~m}$ in 1993 showed about $10 \mathrm{~kg} \mathrm{~N} \mathrm{ha}^{-1}$ accumulation of mineral $\mathrm{N}\left(\mathrm{NH}_{4}\right.$ plus $\left.\mathrm{NO}_{3}-\mathrm{N}\right)$ at the highest treatment level (112 $\mathrm{kg} \mathrm{N} \mathrm{ha}^{-1}$ ) only. ${ }^{[3]}$ The corn research was carried out from 1969 to 1983 on a Sharpsburg silty clay loam (fine, montmorillonitic, mesic Typic Argiudoll) at the Nebraska Agricultural Experiment Station Field Laboratory near Mead, NE. Fertilizer was applied at rates of $0,90,180$, and $270 \mathrm{~kg} \mathrm{~N}^{-1}$ to 9.1 by $20 \mathrm{~m}$ plots. Profile sampling $12 \mathrm{yr}$ after initiation showed $10 \%$ of applied $\mathrm{N}$ had accumulated as $\mathrm{NO}_{3}-\mathrm{N}$ in the upper $1.8 \mathrm{~m}$ of the $270 \mathrm{~kg} \mathrm{~N} \mathrm{ha}^{-1}$ treated plots. Soil analysis for other treatments was not reported. ${ }^{[2]}$

\section{RESULTS AND DISCUSSION}

\section{Crop Response to Nitrogen and Nitrogen Use Efficiency}

Average grain yields increased and NUE decreased significantly in response to fertilizer-N for winter wheat (Fig. 1). Nitrogen use efficiency was calculated as: 100 [harvested $\mathrm{N}$ of fertilized-harvested $\mathrm{N}$ of control]/ $\mathrm{N}$ rate. ${ }^{[1]}$ The five $\mathrm{N}$ rates, in increments of $22.4 \mathrm{~kg} \mathrm{ha}^{-1}$, included four rates where average yield response to $\mathrm{N}$ was positive, and a high rate that decreased yield slightly from maximum. This yield response to $\mathrm{N}$ is typical; the average 


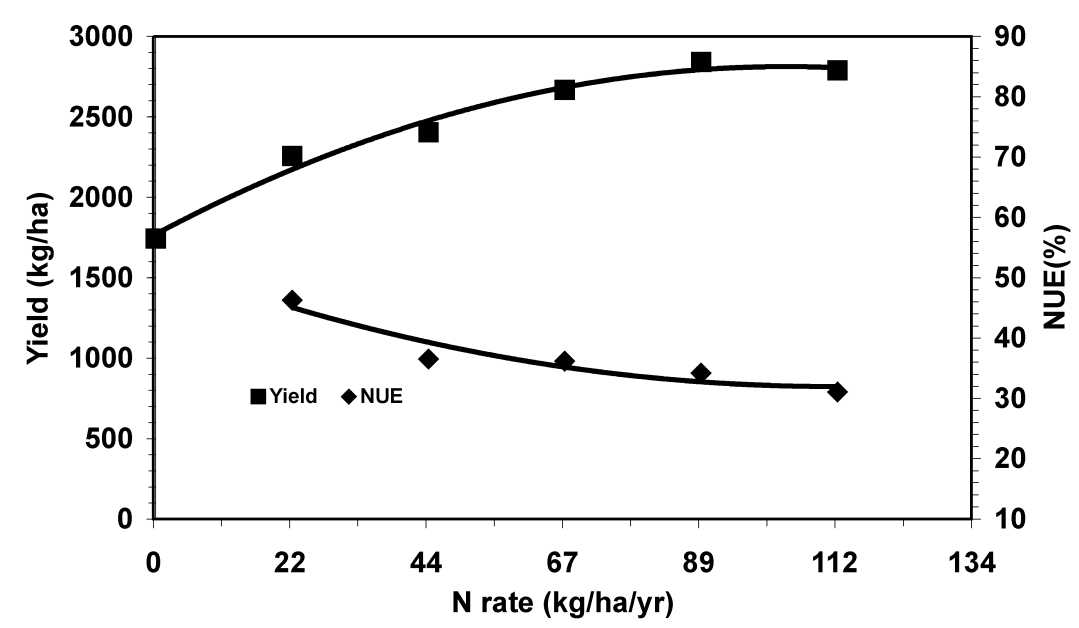

Figure 1. Effect of annually applied fertilizer-N on average yield and NUE of winter wheat (1971-2000, Lahoma, OK).

maximum yield was obtained from an $\mathrm{N}$ rate four times higher than the first increment of $\mathrm{N}$ applied, which has an average NUE of only $48 \%$. Grain $\mathrm{N}$ uptake averaged $37 \mathrm{~kg}$ for the zero $\mathrm{N}$ rate, $47 \mathrm{~kg}$ for the $22 \mathrm{~kg} \mathrm{~N}$ rate, and $67 \mathrm{~kg} \mathrm{Nha}^{-1}$ for the $90 \mathrm{~kg} \mathrm{Nha}^{-1}$ rate. Since the lowest rate provides less fertilizer-N ( $22 \mathrm{~kg}$ ) than the crop takes up for maximum yield $(40 \mathrm{~kg})$, it is obvious there are factors other than crop need that affect NUE, otherwise NUE should have been near $100 \%$ at the low fertilizer rate.

Average corn yield response to fertilizer-N was similar to that for wheat (Fig. 2). However, there were fewer rates included in this study, the incremental additions were larger, and the average NUE for the first increment of $\mathrm{N}$ was much less $(30.6 \%)$. As in the case for the wheat research, the average NUE is poor for the first increment of fertilizer-N even though it supplied only one-half the fertilizer- $\mathrm{N}$ required for maximum yield. These calculations indicate that, averaged over years, the lowest rates of $\mathrm{N}$ in each study would not likely result in excess mineral $\mathrm{N}$ to be present in the soil.

\section{Evaluating Nitrogen Excesses}

The presence of excess mineral $\mathrm{N}$ is a function of how much fertilizer- $\mathrm{N}$ is applied in relation to how much $\mathrm{N}$ the crop requires. Crop $\mathrm{N}$ requirement, in 


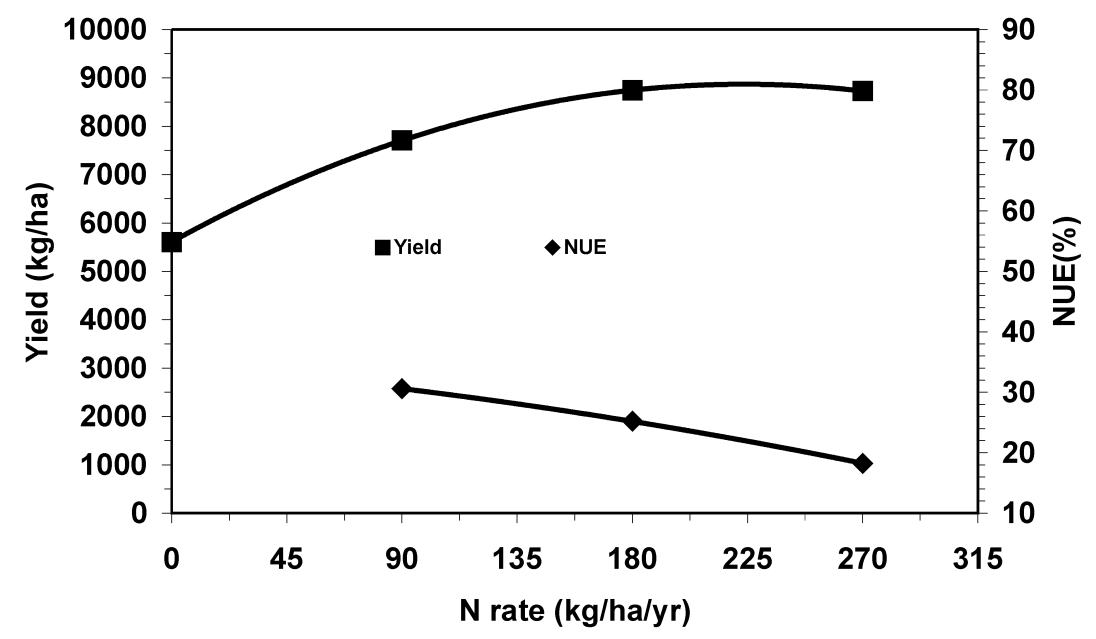

Figure 2. Effect of annually applied fertilizer-N on average yield and NUE of irrigated Corn (1969-83, Mead, NE).

turn, is directly related to potential yield and is supplied by fertilizer and nonfertilizer N. It is usually observed that after several decades of crop production in a system of clean-till, yield without fertilizer $\mathrm{N}$ will be relatively low and constant, consistent with the decreased level of organic-N in soils. ${ }^{[4]}$ Consequently, yields from non-fertilized (control) plots would be expected to be consistently low and decrease over time in these long-term experiments. Figure 3 illustrates a much different response. Wheat yields for the controlplot (where no $\mathrm{N}$ has been applied for 30 years) were highly variable $(\mathrm{CV}=31.5)$ and showed only a slight decreasing trend $\left(7.8 \mathrm{~kg} \mathrm{ha}^{-1} \mathrm{yr}^{-1}\right)$ over the 30-year period [Fig. 3(a)]. The maximum wheat yield achieved by fertilizing each year, identified with total $\mathrm{N}$ requirement of the crop, was almost twice that of the control, but less variable [Fig. 3(b)]. Maximum yield each year was not always obtained from the $90 \mathrm{~kg} \mathrm{Nha}^{-1}$ rate because of annual variability in yield potential and the contribution to crop $\mathrm{N}$ requirement from non-fertilizer sources. Consequently, yield response to fertilizer-N [Fig. $3(\mathrm{c})$ ] was more variable than either the control yields or the maximum yields.

The extent to which a particular fertilizer rate may be excessive was estimated by comparing grain $\mathrm{N}$ uptake for maximum yielding fertilized plots, to $\mathrm{N}$ taken up by the control plots plus the $\mathrm{N}$ applied for maximum yield (Fig. 4). Average excess was $46 \mathrm{~kg} \mathrm{Nha}^{-1}$, for the 14 years where uptake data was available, and ranged from 7 to $86 \mathrm{~kg} \mathrm{~N} \mathrm{ha}^{-1}$. Since these comparisons are 

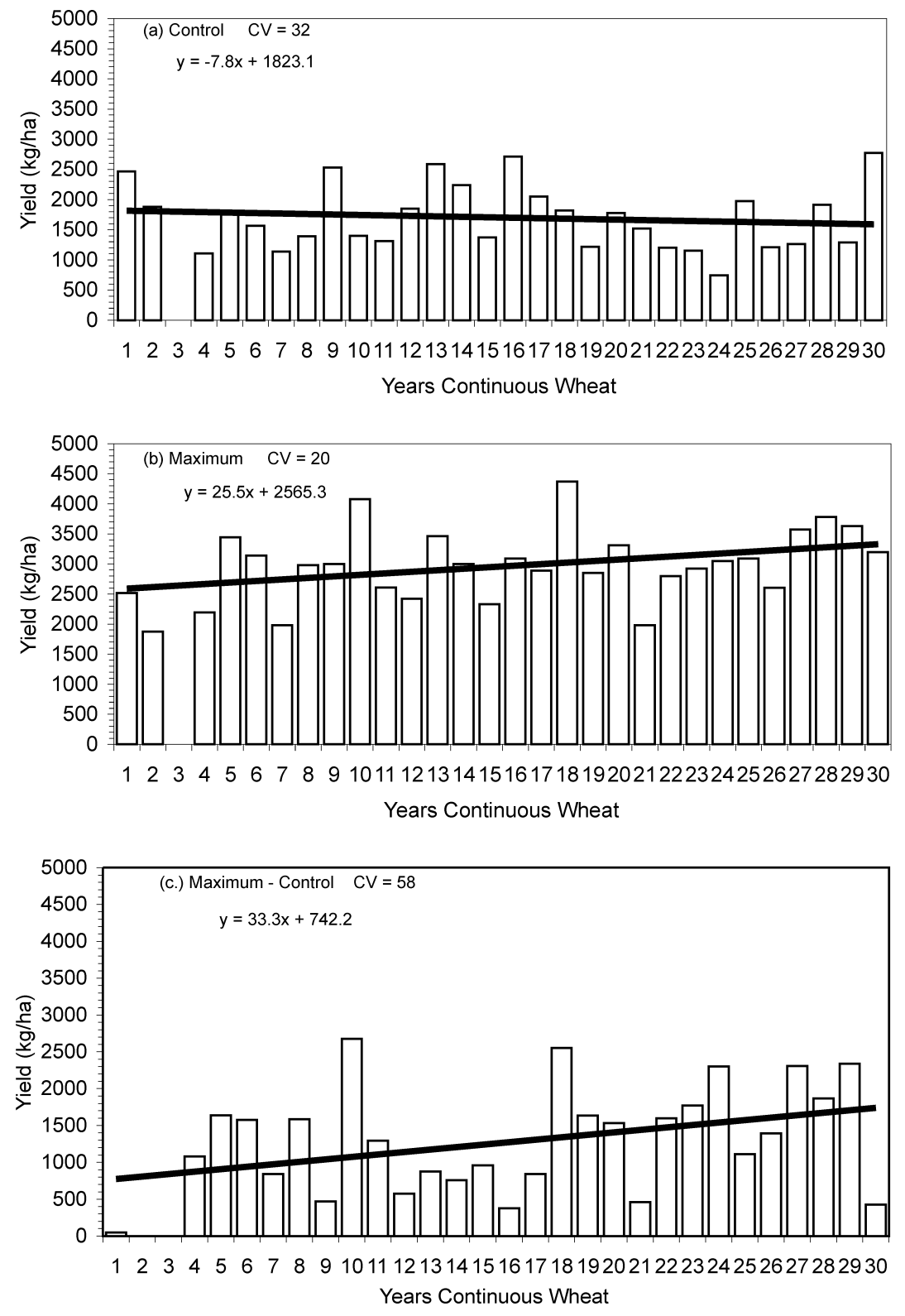

Figure 3. Winter wheat grain yields over time, (a) without fertilizer N; (b) maximum from fertilized plots; and (c) as the increased yield attributable to fertilizer. 


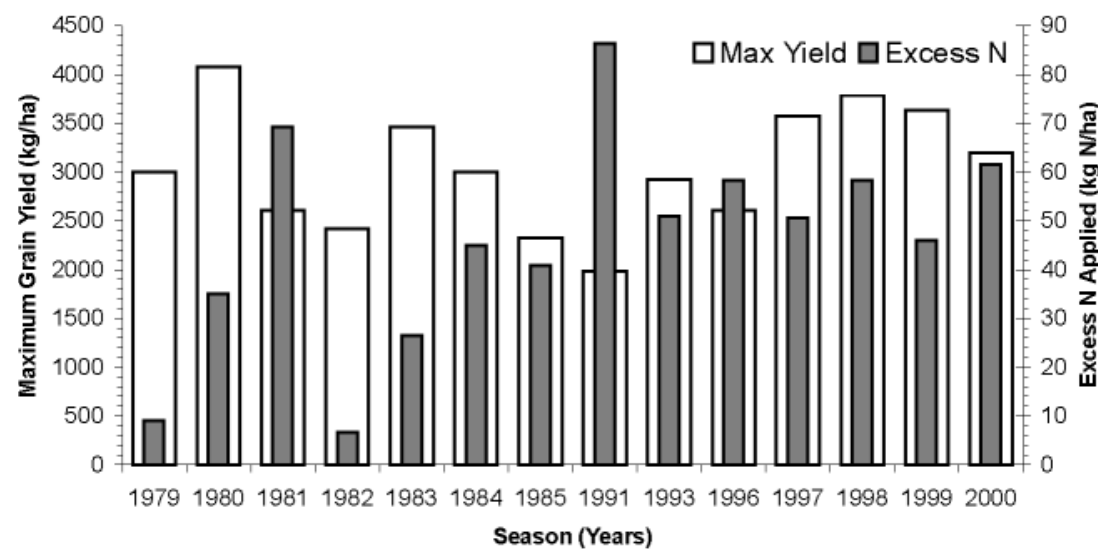

Figure 4. Maximum yield of fertilized plots and the estimated excess $\mathrm{N}$ applied. Excess $\mathrm{N}$ estimated from $\mathrm{N}$ uptake of control yield $+\mathrm{N}$ rate for maximum yield $-\mathrm{N}$ uptake for maximum yield.

between plots that year-after-year receive no fertilizer and plots that receive fertilizer every year, it is reasonable to expect that the common farmer practice of applying a single high rate of fertilizer-N annually would likely result in the presence of large excesses of mineral $\mathrm{N}$ some years. The recommended rate of $\mathrm{N}$ for this location would be $90 \mathrm{~kg} \mathrm{~N}^{-1}$. $^{[5]}$ When excess $\mathrm{N}$ applied is similarly calculated for $90 \mathrm{~kg} \mathrm{Nha}^{-1}$ the excess ranged from 35 to 86 and averaged $59 \mathrm{~kg} \mathrm{Nha}^{-1} \mathrm{yr}^{-1}$.

The relationship between control plot yields and maximum yield of fertilized plots was examined by correlation analyses. The resulting $R^{2}$ of 0.04 indicated the two variables were unrelated (graph not shown). Apparently whatever environmental conditions are conducive to supplying non-fertilizer $\mathrm{N}$ (mineralized organic-N) in the control plots do not similarly increase yield potential and the need for fertilizer- $\mathrm{N}$ in the fertilized plots.

Expecting that much of the variability in dryland wheat yield response to $\mathrm{N}$ was associated with year-to-year temperature and moisture differences, we examined the Nebraska long-term, irrigated corn data using the same approach (Fig. 5). Like yields of unfertilized wheat, unfertilized corn yields tended to decrease slightly with time. Surprisingly, yield variability was slightly greater for the irrigated, unfertilized corn [Fig. 5(a)]. Maximum fertilized corn yields were less variable and tended to decrease over time [Fig. 5(b)]. Yield response to fertilizer-N, as indicated by the maximum fertilized yield minus the control yield, was also highly variable for irrigated corn. As in the case for winter 

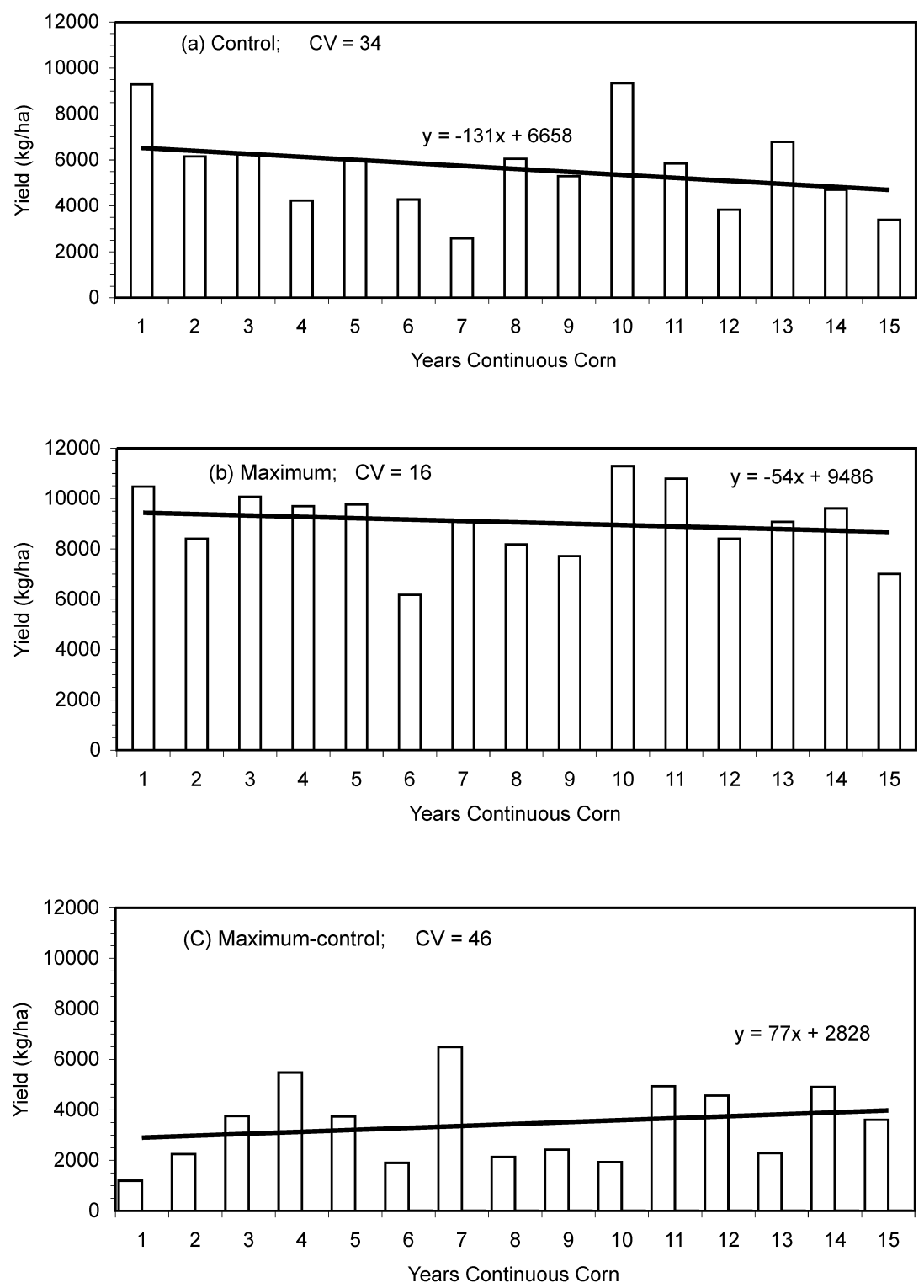

Figure 5. Irrigated corn grain yields over time, (a) without fertilizer N; (b) maximum from fertilized plots; and (c) as the increased yield attributable to fertilizer. 
wheat, it would seem that in many years a single rate of $\mathrm{N}$, such as $180 \mathrm{~kg} \mathrm{ha}^{-1}$ associated with average maximum corn yields, might result in excess mineral$\mathrm{N}$ in the system.

\section{Response Index}

For either the wheat or corn systems, the need for fertilizer-N can be evaluated (after the fact) by simply dividing the maximum yield obtained from fertilizer $\mathrm{N}$ by the yield without fertilizer [graph (b) divided by graph (a), values for Figs. 3 and 5]. This RI shows the extent to which a response to fertilizer-N occurred. Response index values, graphed over time, clearly illustrate that temporal variability for fertilizer-N response is large in both the non-irrigated winter wheat system and the irrigated corn system (Fig. 6) and that the magnitude of response cannot be predicted from year to year. This also indicates that if possible, $\mathrm{N}$ management decisions should be made inseason, after observation or measured evidence identifying the extent to which non-fertilizer $\mathrm{N}$ will be available to support the potential yield.

The implications of temporal variability in the response index are farreaching. In the first three years of both experiments there was little response to fertilizer-N (e.g., $\mathrm{RI} \cong 1$ for wheat and 1.1 to 1.6 for corn). The lack of response was likely a result of past $\mathrm{N}$ fertilization. Initially, evaluation of crop response to $\mathrm{N}$ rate, method of application, or fertilizer material would have been difficult. In contrast, the RI that averaged 2.0 for wheat and 1.8 for corn in years 4-6 (Fig. 6) indicates that the chance of evaluating $\mathrm{N}$ management strategies would have improved. While cropping without $\mathrm{N}$ additions for three years may seem to be logical, it is seldom done in farmer-cooperator experiments. Furthermore, while years 4-6 would have been well suited for $\mathrm{N}$ management experiments in wheat, years $12-14(\mathrm{RI}$ average $=1.3)$ would not have been as sensitive to treatment effects. In both three-year periods the average maximum yield with fertilizer was about $3000 \mathrm{~kg} \mathrm{ha}^{-1}$ with an average difference of $36 \mathrm{~kg} \mathrm{ha}^{-1}$. Similarly for corn, years 8-10 would not have been as good as years $7,11,12,14$, or 15 for evaluating $\mathrm{N}$ management strategies. These results are disconcerting when considering common 3-yr field experiments from which $\mathrm{N}$ recommendations are derived. Nitrogen management strategies that influence NUE, such as topdress (wheat), sidedress (corn), preplant incorporation, foliar application, and use of different materials would not be expected to produce large crop response differences. Therefore, if these are evaluated when the RI is low (e.g. $<1.5)$ it is likely that real differences may be overshadowed by experimental error. On the contrary, 

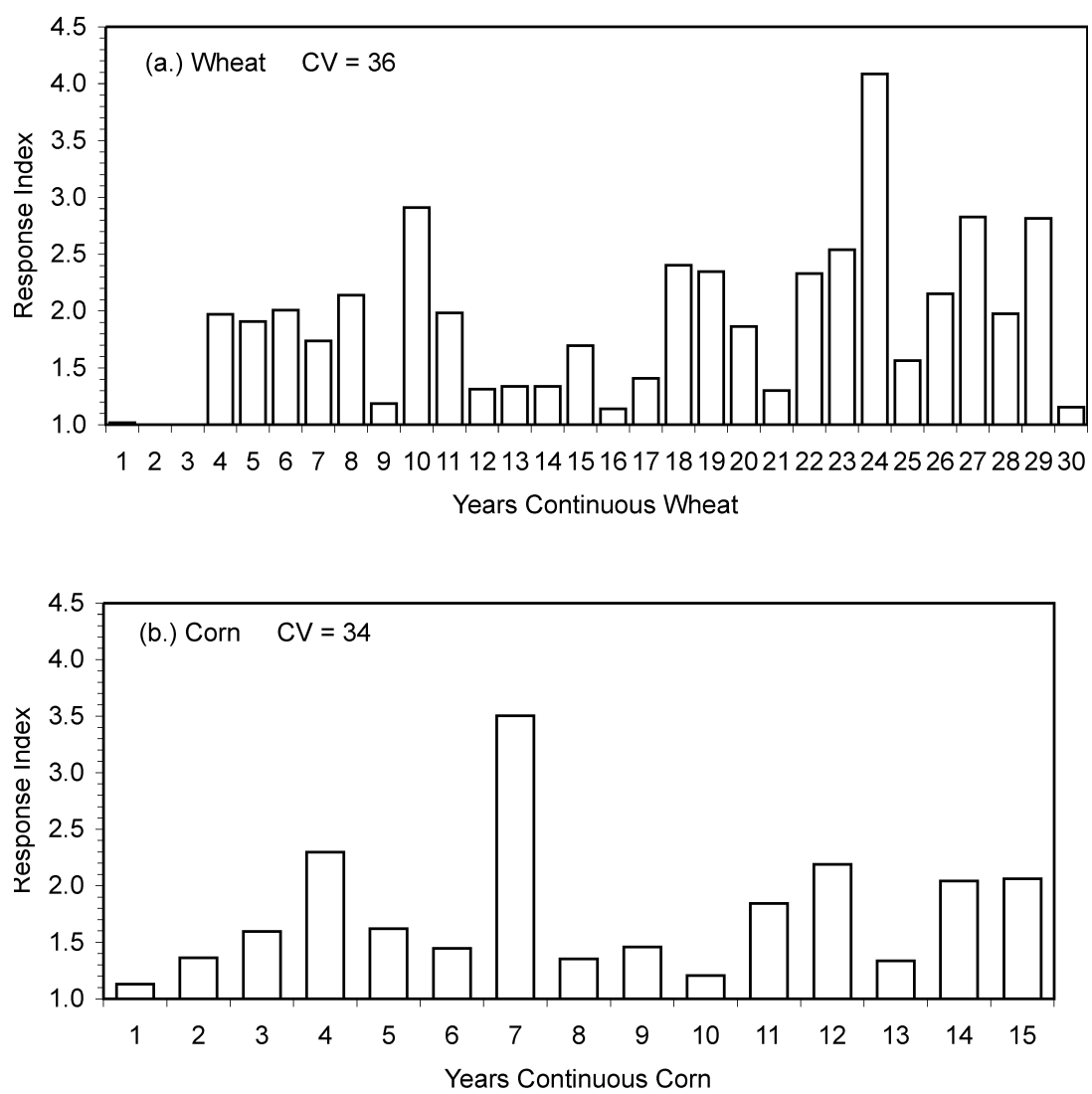

Figure 6. Response Index for (a) wheat and (b) irrigated corn to $\mathrm{N}$ fertilizer over time.

if real differences exist it should be possible to quantify them when the RI is high (e.g. >1.5).

\section{Response Index and Nitrogen Use Efficiency}

Yield of the unfertilized control plot is a common component of RI and NUE as we have calculated them, thus some relationship between RI and NUE should exist. However, since RI provides an indication of the need for 
fertilizer-N, NUE should be expected to improve at a given $\mathrm{N}$ rate as $\mathrm{RI}$ increases and risk of providing excess $\mathrm{N}$ decreases. This was found to be the case when NUE was plotted as a function of RI at the five incremental $\mathrm{N}$ rates for wheat (Fig. 7). Nitrogen Use Efficiency was highest at the lowest $\mathrm{N}$ rate and, except for one point, was above 30 for all RI values. For this lowest $\mathrm{N}$ rate, NUE tended ( $r=0.36$ not significant at 0.05 probability level) to be highest at low RI values and decrease as RI increased. Apparently when growing conditions favor only a small input of external-N, this low rate of fertilizer- $\mathrm{N}$ is used most efficiently. When growing conditions favor a larger input of external-N (large RI), this lowest rate of fertilizer-N is less likely to contribute (either as a result of loss or immobilization) and NUE, though sporadic, tends to decrease.

The higher fertilizer rates $\left(45-112 \mathrm{~kg} \mathrm{Nha}^{-1}\right)$ each provided incrementally greater potential for excess available $\mathrm{N}$ when RI was at its lowest $(<1.2)$, resulting in successive reductions in NUE as rates increase ( $y$-intercept of Fig. 7). The family of response curves resulting from these rates shows the expected increase in NUE at higher RI values representing growing conditions capable of using more external-N. Above the RI value range of 1.2 to 2.9, there is increasingly better fit of curves for each higher rate of $\mathrm{N}$ for the quadratic models as fertilizer- $\mathrm{N}$ is likely to be more in excess at the low RI values and in greater need at the high RI values.

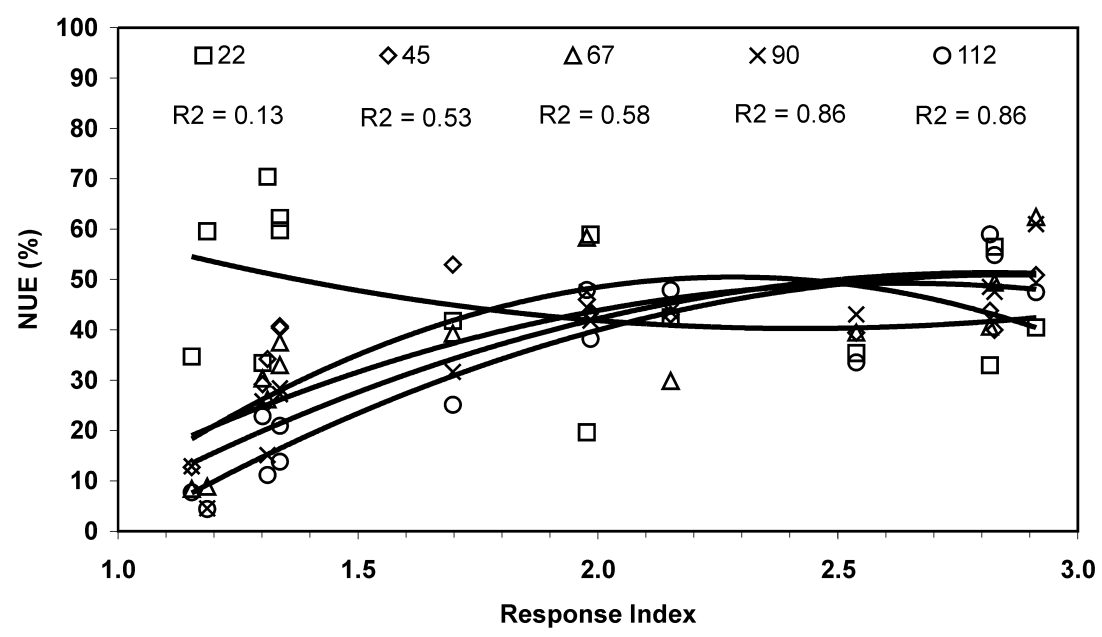

Figure 7. Relationship between NUE by winter wheat and the RI computed for five N rates. 
MARCEl DeKKer, INC. • 270 MAdison AvenUe • NeW YorK, NY 10016

(C2002 Marcel Dekker, Inc. All rights reserved. This material may not be used or reproduced in any form without the express written permission of Marcel Dekker, Inc.

\section{CONCLUSIONS}

Long-term experiments, such as the two examined here, allow reliable evaluation of NUE without the use of isotopic tracers or rigorous analysis of all forms of soil-N. An N-uptake average over many seasons tends to minimize effects of mineral/organic $\mathrm{N}$ turnover variability within and among seasons. Average NUE was below $50 \%$ at the lowest $\mathrm{N}$ rates for both dryland winter wheat in Oklahoma and irrigated corn in Nebraska. Nitrogen use efficiency gradually decreased as $\mathrm{N}$ rates increased to obtain maximum yield. Poor NUE is a result of the soil-plant system leaking mineral-N when it exists in excess of what plants can use. In these experiments the lowest rates seldom approached NUE of $70 \%$ in a given year, even though the next increment of $\mathrm{N}$ resulted in significant yield increases. Because $\mathrm{N}$ fertilizer was preplant incorporated or injected, it was all excessive at application, since there were no crop needs at the time.

In both experiments, crop $\mathrm{N}$ requirement (indicated by the difference between the highest yielding fertilized treatment and the unfertilized control) varied greatly by year, partly because maximum yield varied, but more importantly because of greater variation in yield supported by non-fertilizer-N. Since maximum yield with fertilizer and yield without fertilizer did not vary together, a crop RI was calculated (maximum yield with $\mathrm{N} /$ yield without $\mathrm{N}$ ) as a tool for identifying the extent to which fertilizer-N was needed in a given year. For both systems, RI varied unpredictably over time, from values $<1.5$ for several years to values as high as 4.1 several years after the experiments had been initiated.

We expected available, non-fertilizer $\mathrm{N}$ reserves to become depleted after a few years, resulting in high RI values from then on. While a slight trend for this was found, one of the lowest RI values was in the 30th year of the wheat experiment. One might expect consistently lower RI values and NUE, in a given year, for farmers' fields because they have a history of annual fertilization.

Response index values help provide insight to research of $\mathrm{N}$ management strategies. When RI values are near 1.0 there is little hope of identifying improved strategies because of non-responsive site-years. For purposes of discussion we calculated RI values from published research to illustrate this point. In the first case ${ }^{[6]} \mathrm{N}$ responses (two rates above zero) for two varieties, and three tillage systems (conventional, minimum and no tillage) were evaluated over a 12-year period. They found only 21 significant positive responses out of 72 measures of spring wheat grain yield response. ${ }^{[6]}$ In the first eight years there were only six statistically significant positive responses out of $48(12.5 \%)$. We calculated RI values, averaged for variety by year, and found them to range from 0.86 to 1.15 . In the last four years the RI values, 
similarly calculated, ranged from 1.06 to 1.45 . During the latter period there were 15 positive $\mathrm{N}$ responses out of 24 possibles (62.5\%). Positive responses only occurred when the RI was $>1.11$. Averaged over tillage system and variety, RI was 1.01 for the first eight years and 1.30 for the last four years. During the first eight years it was not possible to identify the need for changing $\mathrm{N}$ management in relation to tillage systems. During the last four years, however, the no-till system $(\mathrm{RI}$ average $=1.47)$ clearly responded differently than conventional $(\mathrm{RI}=1.21)$ and minimum tillage $(\mathrm{RI}=1.21)$.

For a second scenario, ${ }^{[7]}$ when RI values were large, the affects of $\mathrm{N}$ nutrition on crop response could be thoroughly examined. In this case, we calculated RI values that ranged from 1.85 to 7.48 for spring canola (Brassica napus L. var. napus) seed yield, which responded dramatically to $\mathrm{N}$, in a 2-yr study involving five-site years. In this study, it was also possible to evaluate nutrient uptake and oil content relationships because the RI values were large. Nitrogen use efficiency is improved when RI values are high because there is less chance of fertilizer-N being present in excess. Although the cause of high yields supported by non-fertilizer N (and low RI values) is not clear, it is likely a result of better than normal soil environments that promote mineralization of soil organic-N. Apparently the release is well synchronized with $\mathrm{N}$ needs of the developing crop. Continually warm, moist soils during early crop development may lead to low RI values and intermittently hot, cold, and/or dry soils may lead to high RI values. Thus it is apparent that any N management strategy that can include a reasonable in-season prediction of RI, while the crop may still fully respond to $\mathrm{N}$ fertilizer, should result in dramatic improvements in NUE.

A logistical, simple and inexpensive application of this information to improve $\mathrm{N}$ management for crops that normally receive in-season fertilization would be to create a preplant non-limiting $\mathrm{N}$ strip, in each field. If a crop response is visible for this strip, compared to the rest of the field, then the RI is likely high and opportunity for in-season response to $\mathrm{N}$ is high. If the strip is not visibly different from the rest of the field then RI is likely low and chance for response to in-season $\mathrm{N}$ application is minimal. Implementation of this approach for identifying, at least the visible changes in RI, has the potential for greatly improving NUE.

\section{ACKNOWLEDGMENTS}

The authors are grateful to Drs. R. L. Westerman and B. B. Tucker (Emeritus), former faculty of the Plant and Soil Sciences Department of Oklahoma State University, and Professor R.A. Olson (deceased) former 
faculty member in the Department of Agronomy of the University of Nebraska for their foresight to establish and continue the long-term $\mathrm{N}$ fertility studies that made this work possible.

\section{REFERENCES}

1. Raun, W.R.; Johnson, G.V. Improving nitrogen use efficiency for cereal production. Agron. J. 1999, 91, 357-363.

2. Olson, R.A.; Raun, W.R.; Chun, Y.S.; Skopp, J. Nitrogen management and interseeding effects on irrigated corn and sorghum and on soil strength. Agron. J. 1986, 78, 856-862.

3. Raun, W.R.; Johnson, G.V. Soil-plant buffering of inorganic nitrogen in continuous winter wheat. Agron. J. 1995, 87, 827-834.

4. Mullen, R.W.; Freeman, K.W.; Johnson, G.V.; Raun, W.R. The Magruder plots: Long-term wheat fertility research. Better Crops 2001, 85 (2), 6-8.

5. Johnson, G.V.; Raun, W.R.; Zhang, H.; Hattey, J.A. Oklahoma Soil Fertility Handbook, 5th Ed.; Dept. of Plant and Soil Sciences, Oklahoma State University: Stillwater, OK, 2000.

6. Halvorson, A.D.; Black, A.L.; Krupinsky, J.M.; Merrill, S.D.; Wienhold, B.J.; Tanaka D.L. Spring wheat response to tillage system and nitrogen fertilization within a crop-fallow system. Agron. J. 2000, 92, 288-294.

7. Jackson, G.D. Effects of nitrogen and sulfur on canola yield and nutrient uptake. Agron. J. 2000, 92, 644-649. 